\title{
Racial and Socioeconomic Disparities in Access to Primary Care Among People With Chronic Conditions
}

\author{
Leiyu Shi, DrPH, MBA, MPA, Chien-Chou Chen, PhD, Xiaoyu Nie, MS, \\ Jinsheng $Z h u, M S$, and Ruwei $H u, P h D$
}

Objective: The purpose of this study was to examine racial and socioeconomic disparities in access to primary care among people with chronic conditions.

Methods: Data for this study were taken from the household component of the 2010 Medical Expenditure Panel Survey. The analysis primarily focused on adults $\geq 18$ years old. Logistic regressions were conducted among people with chronic conditions to compare primary care attributes between each minority group and their non-Hispanic white counterparts and between individuals with high, above average, or below average socioeconomic status and their low socioeconomic status counterparts, controlling for other individual factors.

Results: Racial disparities were found in having usual source of care (USC), USC provider type, and USC location. However, no disparities were found in ease of contacting or getting to USC as well as the services received. Furthermore, very limited socioeconomic disparities were found after controlling for other individual characteristics, in particular race and insurance status.

Conclusions: More efforts need to be devoted to racial/ethnic minorities with chronic conditions to improve their access to continuous and high-quality primary care. ( $\mathrm{J}$ Am Board Fam Med 2014;27: 189-198.)

Keywords: Access to Health Care, Chronic Disease, Health Care Disparities, Primary Health Care, Quality of Health Care

Chronic conditions are the leading cause of death and disability in the United States. ${ }^{1}$ Each year, 7 of 10 deaths are due to chronic diseases. ${ }^{2}$ In 2008, almost half of adults in the United States had at

This article was externally peer reviewed.

Submitted 3 September 2013; revised 20 November 2013; accepted 25 November 2013.

From the Department of Health Policy and Management (LS) and the Johns Hopkins Primary Care Policy Center (LS, XN, JZ, RH), Johns Hopkins University Bloomberg School of Public Health, Baltimore, MD; the Department of International Business, Ling Tung University, Taichung City, Taiwan (C-CC); and the School of Public Health and Center of Migrant Health Policy, Sun Yat-sen University, Guangzhou, Guangdong, PR China (RH).

Funding: The study was supported by the Johns Hopkins Primary Care Policy Center and a Guangzhou medicinal science and technology major grant (no. 20121A031002, "Empirical research on mental health legislation in Guangzhou").

Conflict of interest: none declared.

Corresponding author: Ruwei $\mathrm{Hu}, \mathrm{PhD}$, School of Public Health and Center of Migrant Health Policy, Sun Yat-sen University, 74 Zhongshan Road 2, Guangzhou 510080, China (E-mail: huruwei@mail.sysu.edu.cn). least one chronic condition. The prevalence of chronic diseases increased not only among the elderly population but also among adults between 20 and 64 years old. According to Paez et al, ${ }^{3}$ from 1996 to 2005 there was an increase from $32.4 \%$ to $63.1 \%$ of people with at least one chronic condition. Although the elderly people $>64$ years old had the highest burden of multiple chronic conditions during this time period, there was a $9.7 \%$ increase in adults between the ages of 45 and 64 who had $\geq 3$ chronic conditions. ${ }^{3}$

Moreover, chronic conditions accounted for a large proportion of the growth in health care spending. ${ }^{4}$ Out-of-pocket spending increased along with the increase of chronic conditions, with one estimate of a $39.4 \%$ increase per person between 1996 and 2005. Another study showed that, among countries in the Organisation for Economic Co-operation and Development, for every percentage increase in the chronic diseases mortality rate among 
the working-age population, there is a $0.05 \%$ decrease in economic growth. ${ }^{5}$

Racial/ethnic disparities in access to care are lingering in the United States. ${ }^{6-11}$ In 2007, there was a difference of 5 years in life expectancy between non-Hispanic whites and African Americans. ${ }^{12}$ Racial/ethnic disparities exist in the care for chronic conditions as well. For example, according to a study of older adults with diabetes in California, ${ }^{13}$ compared with their white counterparts, African Americans were more likely to go to the emergency department to seek care for diabetes; Hispanic individuals were less likely to take medicines to control cholesterol; and Asian individuals were less likely to either test their blood glucose regularly or have foot examinations. Similar results also were seen in the treatment of unruptured intracranial aneurysms, ${ }^{14}$ cardiovascular diseases, ${ }^{15}$ and chronic kidney diseases, ${ }^{16}$ to name just a few.

Improving health care and health outcomes for chronic conditions and increasing the proportion of people with a usual primary care provider are among the goals of Healthy People 2020. ${ }^{17}$ Research has demonstrated the essential impact of primary care on improving access to care, enhancing patient outcomes, narrowing health disparities, and reducing health care costs. ${ }^{18,19}$ Primary care is expected to play a significant role in the care and management of chronic conditions. ${ }^{20}$ However, few studies have examined racial and socioeconomic disparities in access to primary care for people with chronic diseases. To the extent disparity exists, it would have a greater effect on their health. The purpose of this study was to examine racial and socioeconomic disparities in access to primary care among people with chronic conditions using the latest nationally representative survey data.

\section{Methods \\ Data}

Data for this study were from the household component of the 2010 Medical Expenditure Panel Survey (MEPS), a nationally representative survey of families and noninstitutionalized individuals in the United States conducted by the Agency for Health care Research and Quality. ${ }^{21}$ Detailed discussion of the complex design of MEPS has been published elsewhere. ${ }^{22}$ This study focused on adults 18 years of age or older and contained 23,434 observations.

\section{Measures}

The household component of the MEPS collects information on demographic characteristics, health conditions, health status, use of medical services, charges and source of payments, access to care, satisfaction with care, health insurance coverage, income, and employment. ${ }^{21}$ In this study, dependent variables were 12 characteristics of primary care access and services experienced at the patient level. The independent variables were race/ethnicity and socioeconomic status. Individual characteristics affecting access to primary care were included as covariates.

\section{Characteristics of Primary Care Access and Services}

Eight questions were selected to reflect the characteristics of primary care access. The first one addressed whether an individual has usual source of care (USC). The second asked about the type of USC provider, that is, a health care facility or a specific provider. The next 2 questions were about USC provider specialty and location of USC, which was dichotomized into office-based and hospital/facility-based. The remaining 4 questions assessed ease of accessing USC, specifically (1) difficulty in contacting USC by phone, (2) having office hours during nights/weekends, (3) time taken to get to USC, and (4) difficulty in getting to USC.

Another 4 questions were selected to assess primary care services, including going to USC for preventive health care, going to USC for referrals, provider asking about other treatments, and provider listening to patients.

\section{Chronic Conditions}

The indicator for chronic conditions was drawn from variables indicating the presence of the following major chronic conditions in the United States: arthritis; active asthma; diabetes; emphysema; high blood pressure; ischemic heart disease (coronary heart disease, angina, heart attack, or any other heart-related disease); and stroke. For each of the conditions listed, the following question was asked: "Have/Has [person] ever been told by a doctor or other health professional that [person] had [condition]." For asthma, those with an affirmative answer were further asked: "Do/Does [person] still have asthma?" In this analysis, only those with active asthma (those who answered affirmatively to the follow-up question) were included among those with chronic conditions. Consistent 
with the Agency for Health care Research and Quality, an individual was classified as having a chronic condition(s) if he or she reported one or more of the conditions listed above.

\section{Race/Ethnicity}

Race/ethnicity was categorized into 5 groups: nonHispanic white, non-Hispanic black, Hispanic, nonHispanic Asian, and other.

\section{Individual Characteristics}

Following the framework for access to care developed by Andersen, ${ }^{23}$ we included the following measures of individual characteristics: age (18-64 and $>64$ years old); sex; health insurance (private, public, and no insurance); highest education ( $1=$ below bachelor's degree, 2 = bachelor's degree or higher); employment status ( 1 = unemployed, 2 = employed); poverty status ( $1=$ poor/negative/near poor/low income, 2 = middle income/high income); metropolitan statistical area; census region (Northeast, Midwest, South, and West); self-perceived health status; self-perceived mental health status; help with activities of daily living (ADLs); and help with instrumental ADLs. A composite measure of socioeconomic status (SES) also was developed based on education, employment status, and poverty status (see codings above) and was categorized into 4 groups: high SES (if responses to the 2 measures were both 2s); above-average SES (if responses to any 2 of the 3 measures were 2 s); below-average SES (if responses to any 2 of the 3 measures were 1s); and low SES (if responses to the 3 measures were all 1s).

\section{Statistical Analysis}

Descriptive analysis was first conducted to examine the distributions of individual characteristics for the whole population as well as the groups with and without chronic conditions. Second, bivariate analysis of each primary care attribute was performed among people with chronic conditions by racial/ ethnic group. Last, among people with chronic conditions, logistic regression was conducted to compare primary care attributes between each minority group and their non-Hispanic white counterparts and between individuals with high, aboveaverage, or below-average SES and their counterparts with low SES, controlling for other individual characteristics.

\section{Results}

\section{Descriptive Analysis Results}

Table 1 presents the results of the descriptive analysis of individual characteristics for adults both with and without chronic conditions. Of people without chronic conditions, $3.7 \%$ were $>64$ years old, compared with $30.6 \%$ of people with chronic conditions. Those with chronic conditions were more likely to be non-Hispanic white and nonHispanic black. Furthermore, 9.9\% of those without chronic conditions compared with $24.2 \%$ of those with chronic conditions had public insurance, whereas $20.7 \%$ of those without chronic conditions versus $10.0 \%$ of those with chronic conditions were uninsured. Moreover, based on each individual's education, employment status, and poverty status, the overall SES of those without chronic conditions was significantly higher than those with chronic conditions. In addition, people with chronic conditions were more likely to have fair or poor selfperceived health status and mental health statusand were more likely to need help for ADLs and instrumental ADLs-than those without chronic conditions.

\section{Bivariate Analysis Results}

Table 2 shows the bivariate analysis results of primary care attributes by race/ethnicity for adults with chronic conditions. Racial/ethnic disparities were found in several attributes. First, of the racial/ ethnic groups, Hispanic individuals were the least likely to have a USC, followed by non-Hispanic black and non-Hispanic Asian individuals. More than half of the non-Hispanic black and Hispanic individuals reported a facility as their USC rather than a person or a person in a facility. A significantly smaller proportion of Hispanic individuals' USC were office-based compared with the other 3 groups. No significant differences were found regarding difficulties contacting USC by phone among the $4 \mathrm{racial} / \mathrm{ethnic}$ groups. Significantly more nonHispanic Asian individuals reported that their USC have office hours at night or during weekends than the other groups. In terms of the time it takes and difficulty of getting to the USC, there was no significant difference among the 4 groups. As for primary care services, most individuals reported going to a USC for preventive health care and referrals. However, significantly more non-Hispanic white 
Table 1. Characteristics of Adults With Versus Without Chronic Conditions

\begin{tabular}{|c|c|c|c|c|}
\hline Characteristics & Sample (n)* & Total & Without Chronic Conditions & With Chronic Conditions \\
\hline \multicolumn{5}{|l|}{ Age $(\text { years })^{\dagger}$} \\
\hline $18-64$ & 18,672 & $82.8(0.5)$ & $96.3(0.2)$ & $69.5(0.7)$ \\
\hline$\geq 64$ & 3,594 & $17.2(0.5)$ & $3.7(0.2)$ & $30.6(0.7)$ \\
\hline \multicolumn{5}{|l|}{$\operatorname{Sex}^{\dagger}$} \\
\hline Male & 10,287 & $48.4(0.3)$ & $50.1(0.5)$ & $46.8(0.5)$ \\
\hline Female & 11,979 & $51.6(0.3)$ & $49.9(0.5)$ & $53.2(0.5)$ \\
\hline \multicolumn{5}{|l|}{ Race/ethnicity ${ }^{\dagger}$} \\
\hline Non-Hispanic white & 10,506 & $67.7(1.0)$ & $62.9(1.3)$ & $72.3(0.9)$ \\
\hline Non-Hispanic black & 4,193 & $11.5(0.7)$ & $10.5(0.7)$ & $12.5(0.7)$ \\
\hline Hispanic & 5,399 & $14.1(0.8)$ & $18.3(1.0)$ & $10.0(0.7)$ \\
\hline Non-Hispanic Asian & 1,705 & $4.7(0.4)$ & $6.3(0.6)$ & $3.2(0.4)$ \\
\hline Other & 463 & $2.0(0.2)$ & $2.0(0.3)$ & $2.0(0.3)$ \\
\hline \multicolumn{5}{|l|}{ Health insurance ${ }^{\dagger}$} \\
\hline Private & 12,914 & $67.6(0.7)$ & $69.5(0.9)$ & $65.8(0.8)$ \\
\hline Public & 4,745 & $17.1(0.5)$ & $9.9(0.5)$ & $24.2(0.7)$ \\
\hline No insurance & 4,607 & $15.3(0.5)$ & $20.7(0.7)$ & $10.0(0.4)$ \\
\hline \multicolumn{5}{|l|}{ Education $^{\dagger}$} \\
\hline Less than bachelor's degree & 17,143 & $71.8(0.6)$ & $70(0.8)$ & $73.6(0.7)$ \\
\hline Bachelor's degree or higher & 4,944 & $28.2(0.6)$ & $30(0.8)$ & $26.4(0.7)$ \\
\hline \multicolumn{5}{|l|}{ Employment status ${ }^{\dagger}$} \\
\hline Unemployed & 8,070 & $33.3(0.6)$ & $21.8(0.5)$ & $44.5(0.8)$ \\
\hline Employed & 14,106 & $66.7(0.6)$ & $78.2(0.5)$ & $55.5(0.8)$ \\
\hline \multicolumn{5}{|l|}{ Poverty $^{\ddagger}$} \\
\hline Poor/negative/near poor/low income & 8,753 & $30.3(0.7)$ & $29.5(0.8)$ & $31.2(0.8)$ \\
\hline Middle/high income & 13,513 & $69.7(0.7)$ & $70.5(0.8)$ & $68.8(0.8)$ \\
\hline \multicolumn{5}{|l|}{ Socioeconomic status $^{\dagger}$} \\
\hline High & 3,415 & $20.2(0.5)$ & $23.6(0.7)$ & $16.9(0.6)$ \\
\hline Above average & 7,702 & $38.5(0.6)$ & $41.3(0.7)$ & $35.8(0.7)$ \\
\hline Below average & 6,651 & $26.9(0.5)$ & $25.3(0.7)$ & $28.4(0.6)$ \\
\hline Low & 4,234 & $14.4(0.4)$ & $9.8(0.4)$ & $18.9(0.6)$ \\
\hline \multicolumn{5}{|l|}{ Metropolitan statistical area $^{\dagger}$} \\
\hline No & 3,138 & $15.8(1.3)$ & $13.3(1.2)$ & $18.1(1.5)$ \\
\hline Yes & 19,128 & $84.2(1.3)$ & $86.7(1.2)$ & $81.9(1.5)$ \\
\hline \multicolumn{5}{|l|}{ Census region $^{\dagger}$} \\
\hline Northeast & 3,522 & $18.5(0.7)$ & $18.5(0.8)$ & $18.4(0.8)$ \\
\hline Midwest & 4,543 & $21.7(0.7)$ & $20.3(0.8)$ & $23.1(0.7)$ \\
\hline South & 8,337 & $36.7(0.9)$ & $35.9(1.1)$ & $37.5(1.0)$ \\
\hline West & 5,864 & $23.1(0.8)$ & $25.3(0.9)$ & $21.1(0.8)$ \\
\hline \multicolumn{5}{|l|}{ Perceived health status ${ }^{\dagger}$} \\
\hline Excellent/very good/good & 19,019 & $87.2(0.3)$ & $95.3(0.2)$ & $79.4(0.5)$ \\
\hline Fair/poor & 3,237 & $12.8(0.3)$ & $4.7(0.2)$ & $20.6(0.5)$ \\
\hline \multicolumn{5}{|l|}{ Perceived mental health status ${ }^{\dagger}$} \\
\hline Excellent/very good/good & 20,462 & $92.6(0.3)$ & $96.1(0.3)$ & $89.2(0.4)$ \\
\hline Fair/poor & 1,792 & $7.4(0.3)$ & $3.9(0.3)$ & $10.8(0.4)$ \\
\hline \multicolumn{5}{|l|}{ Need help with ADLs ${ }^{\dagger}$} \\
\hline No & 21,828 & $98.4(0.1)$ & $99.6(0.1)$ & $97.2(0.2)$ \\
\hline Yes & 389 & $1.6(0.1)$ & $0.4(0.1)$ & $2.8(0.2)$ \\
\hline
\end{tabular}

Continued 
Table 1. Continued

\begin{tabular}{lrrrr}
\hline Characteristics & Sample $(\mathrm{n})^{*}$ & Total & Without Chronic Conditions & With Chronic Conditions \\
\hline Need help with instrumental ADLs ${ }^{\dagger}$ & & & & \\
No & 21,464 & $96.6(0.2)$ & $99.1(0.1)$ & $94.2(0.3)$ \\
Yes & 769 & $3.4(0.2)$ & $0.9(0.1)$ & $5.8(0.3)$ \\
\hline
\end{tabular}

Data are \% (standard error) unless otherwise indicated.

${ }^{*}$ Weighted $\mathrm{N}=230,945,258$.

${ }^{\dagger} P<.001$ based on $\chi^{2}$ tests of the differences between those with and without chronic conditions.

${ }^{\ddagger} P<.05$ based on $\chi^{2}$ tests of the differences between those with and without chronic conditions.

ADL, activity of daily living.

(84.0\%) and non-Hispanic black (85.6\%) people reported that their USC providers asked about other treatments than non-Hispanic Asian (80.8\%) and Hispanic (79.4\%) people.

\section{Logistic Regression Results}

Table 3 displays logistic regression results for each primary care attribute, comparing each minority group with their non-Hispanic white counterparts. The 3 minority groups were found to have significantly lower odds of having a USC than their non-Hispanic white counterparts. Furthermore, non-Hispanic black and Hispanic individuals were found to have higher odds of reporting a facility rather than person/person at a facility as their USC. USC provider specialties for all 3 minority groups were either equally (non-Hispanic black and Hispanic individuals) or more likely (non-Hispanic Asian individuals) to be primary care. Moreover, there were significantly lower odds for all 3 minority groups reporting a USC in doctors' offices than the non-Hispanic white group. The USCs of Hispanic and non-Hispanic Asian individuals were found more likely have office hours at night or during weekends, and no racial disparities were found in terms of ease of getting to the USC. Finally, there were no significant differences in preventive health care, referrals, or providers asking about other treatments. However, non-Hispanic black individuals had $60 \%$ lower odds of reporting that their USC providers listened to them than the non-Hispanic white group.

Table 4 presents logistic regression results from the same regression model for primary care attributes comparing individuals with different SES. Very limited disparities were found after controlling for other individual characteristics, in particular race and insurance status. Association was found only between difficulty in getting to USC and SES.
Those with the lowest SES were more likely to report difficulties getting to their USC than other SES groups.

\section{Discussion}

Using the latest survey data, we found that racial/ ethnic disparities in access to primary care among patients with chronic conditions persist, mainly in terms of having a USC, USC provider type, and USC location. Minority groups were less likely to have a USC. They were more likely to report facility-based USCs and hospitals as USCs rather than specific doctors and doctors' offices. However, no racial disparities were found in contacting or getting to USC, and USCs of the minority groups were more likely to have office hours at night and during weekends. Moreover, there were no differences in the primary care services accessed or received. Finally, limited disparities were found among groups with different SES.

Starfield ${ }^{24}$ defined the 4 domains of primary care: first contact, longitudinality, comprehensiveness, and coordination. Many attributes examined in this study reflect those domains. The primary care access measures correspond to the first 2 domains, whereas the primary care services measures are relevant to the last 2 domains. Based on this study, we found that racial/ethnic disparities in the first contact and longitudinality domains still exist among adults with chronic conditions. Nonetheless, no racial/ethnic disparities were found in the comprehensiveness and coordination domains of primary care among patients with chronic conditions, indicating that once patients have continuous access to primary care, racial/ethnic disparities are no longer significant.

People with chronic conditions typically have more health care needs, which can be better ad- 
Table 2. Race/Ethnicity and Primary Care Access and Services Among Adults With Chronic Conditions

\begin{tabular}{|c|c|c|c|c|c|}
\hline \multirow[b]{2}{*}{ Primary Care Attributes } & \multirow[b]{2}{*}{ Sample (n)* } & \multicolumn{4}{|c|}{ Race/Ethnicity } \\
\hline & & $\begin{array}{c}\text { Non-Hispanic } \\
\text { White }\end{array}$ & $\begin{array}{l}\text { Non-Hispanic } \\
\text { Black }\end{array}$ & Hispanic & $\begin{array}{c}\text { Non-Hispanic } \\
\text { Asian }\end{array}$ \\
\hline \multicolumn{6}{|l|}{ Access } \\
\hline Have USC ${ }^{\dagger}$ & $113,314,477$ & & & & \\
\hline No & 1688 & $11.9(0.6)$ & $17.9(1.0)$ & $21.6(1.2)$ & $17.4(2.3)$ \\
\hline Yes & 8847 & $88.1(0.6)$ & $82.1(1.0)$ & $78.4(1.2)$ & $82.6(2.3)$ \\
\hline Type of USC ${ }^{\dagger}$ & $97,611,079$ & & & & \\
\hline Facility & 4323 & $44.6(1.5)$ & $51.1(1.5)$ & $56.5(2.1)$ & $42.9(3.7)$ \\
\hline Person/Person in facility & 4524 & $55.4(1.5)$ & $48.9(1.5)$ & $43.5(2.1)$ & $57.1(3.7)$ \\
\hline USC specialty & $52,313,127$ & & & & \\
\hline Primary care & 4196 & $92.5(0.7)$ & $93(1.1)$ & $92.9(1.6)$ & $97.2(1.1)$ \\
\hline Other & 328 & $7.5(0.7)$ & $7(1.1)$ & $7.1(1.6)$ & $2.8(1.1)$ \\
\hline USC location $^{\dagger}$ & $97,575,176$ & & & & \\
\hline Office & 7031 & $86(0.9)$ & $77.3(1.4)$ & $69(2.1)$ & $79.9(2.5)$ \\
\hline Hospital & 1813 & $14(0.9)$ & $22.7(1.4)$ & $31(2.1)$ & $20.1(2.5)$ \\
\hline Difficulty in contacting USC by phone & $94,131,693$ & & & & \\
\hline Not very difficult & 8100 & $95.4(0.4)$ & $95.0(0.7)$ & $94.2(0.7)$ & $95.3(1.4)$ \\
\hline Very difficult & 428 & $4.6(0.4)$ & $5.0(0.7)$ & $5.8(0.7)$ & $4.7(1.4)$ \\
\hline USC has office ${ }^{\dagger}$ hours nights/weekends & $87,156,665$ & & & & \\
\hline No & 5032 & $65.7(1.3)$ & $65.3(1.7)$ & $60.1(1.9)$ & $47.6(3.5)$ \\
\hline Yes & 2873 & $34.3(1.3)$ & $34.7(1.7)$ & $39.9(1.9)$ & $52.4(3.5)$ \\
\hline How long it takes to get to USC & $97,487,270$ & & & & \\
\hline$\leq 30$ minutes & 7799 & $89(0.7)$ & $87.5(1.2)$ & $89.6(1)$ & $88.1(2.1)$ \\
\hline$>30$ minutes & 1029 & $11(0.7)$ & $12.5(1.2)$ & $10.4(1)$ & $11.9(2.1)$ \\
\hline How difficult it is to get to USC & $97,457,495$ & & & & \\
\hline Difficulty & 600 & $5.9(0.5)$ & $6.8(0.7)$ & $7.1(0.8)$ & $6.7(1.5)$ \\
\hline Not difficult & 8233 & $94.1(0.5)$ & $93.2(0.7)$ & $92.9(0.8)$ & $93.3(1.5)$ \\
\hline \multicolumn{6}{|l|}{ Services } \\
\hline Go to USC for preventive health care & $97,563,540$ & & & & \\
\hline No & 203 & $2.3(0.3)$ & $2.4(0.4)$ & $2.4(0.5)$ & $1.3(0.5)$ \\
\hline Yes & 8634 & $97.7(0.3)$ & $97.6(0.4)$ & $97.6(0.5)$ & $98.7(0.5)$ \\
\hline Go to USC for referrals & $97,512,933$ & & & & \\
\hline No & 218 & $2.5(0.3)$ & $2.1(0.4)$ & $3.1(0.6)$ & $3.9(1.6)$ \\
\hline Yes & 8612 & $97.5(0.3)$ & $97.9(0.4)$ & $96.9(0.6)$ & $96.1(1.6)$ \\
\hline USC provider asks about other treatments ${ }^{\ddagger}$ & $94,279,152$ & & & & \\
\hline No & 1444 & $16.0(0.8)$ & $14.4(1.0)$ & $20.6(1.9)$ & $19.2(2.5)$ \\
\hline Yes & 7089 & $84.0(0.8)$ & $85.6(1.0)$ & $79.4(1.9)$ & $80.8(2.5)$ \\
\hline USC provider listens $^{\dagger}$ & $88,642,483$ & & & & \\
\hline No & 73 & $0.5(0.1)$ & $1.8(0.4)$ & $0.9(0.3)$ & $0.9(0.5)$ \\
\hline Yes & 7803 & $99.5(0.1)$ & $98.2(0.4)$ & $99.1(0.3)$ & $99.1(0.5)$ \\
\hline
\end{tabular}

Data are \% (standard error) unless otherwise indicated.

*Bold values indicate total weighted sample.

${ }^{\dagger} P<.001$, based on $\chi^{2}$ tests of the differences between those with and without chronic conditions.

${ }^{\ddagger} P<.01$ based on $\chi^{2}$ tests of the differences between those with and without chronic conditions.

USC, usual source of care.

dressed by comprehensive, continuous, and coordinated primary care. ${ }^{25-27}$ The persistent racial/ethnic disparities in access to primary care demonstrated in this study are expected to lead to unmet health needs, poor access to care, and low quality of care among minority groups. ${ }^{19,28-30}$ In addition, people who were unsatisfied with their USC or failed to get continuous primary care from their USC are more likely to have nonurgent emergency department visits and hospitalizations. ${ }^{31,32}$ Therefore, more ef- 
Table 3. Logistic Regression Odds Ratios for Attributes of Primary Care Access and Services According to Race/Ethnicity Among People With Chronic Conditions

\begin{tabular}{|c|c|c|c|}
\hline \multirow[b]{2}{*}{ Primary Care Attributes } & \multicolumn{3}{|c|}{ Race/Ethnicity } \\
\hline & $\begin{array}{l}\text { Non-Hispanic Black vs. } \\
\text { Non-Hispanic White }\end{array}$ & $\begin{array}{c}\text { Hispanic vs. } \\
\text { Non-Hispanic White }\end{array}$ & $\begin{array}{l}\text { Non-Hispanic Asian vs. } \\
\text { Non-Hispanic White }\end{array}$ \\
\hline \multicolumn{4}{|l|}{ Access } \\
\hline \multicolumn{4}{|l|}{ Have USC } \\
\hline Yes & $0.8^{*}(0.7-1.0)$ & $0.8^{\dagger}(0.6-0.9)$ & $0.7 *(0.5-0.9)$ \\
\hline No & 1.0 & 1.0 & 1.0 \\
\hline \multicolumn{4}{|l|}{ Type of USC } \\
\hline Facility & $1.4^{\ddagger}(1.2-1.6)$ & $1.4^{\dagger}(1.1-1.7)$ & $0.9(0.6-1.2)$ \\
\hline Person/person in facility & 1 & 1 & 1 \\
\hline \multicolumn{4}{|l|}{ USC specialty } \\
\hline Primary care & $1.1(0.7-1.6)$ & $1.4(0.8-2.5)$ & $3.0^{\dagger}(1.3-6.8)$ \\
\hline Other & 1 & 1 & 1 \\
\hline \multicolumn{4}{|l|}{ USC location } \\
\hline Office & $0.5^{\ddagger}(0.4-0.6)$ & $0.4^{\ddagger}(0.3-0.5)$ & $0.7^{*}(0.5-1.0)$ \\
\hline Hospital & 1 & 1 & 1 \\
\hline \multicolumn{4}{|c|}{ Difficulty in contacting USC by phone } \\
\hline Very difficult & $0.9(0.6-1.3)$ & $0.9(0.7-1.3)$ & $1.0(0.5-2.0)$ \\
\hline Not very difficult & 1 & 1 & 1 \\
\hline \multicolumn{4}{|c|}{ USC has office hours nights/weekends } \\
\hline Yes & $1.1(0.9-1.4)$ & $1.3^{\dagger}(1.1-1.6)$ & $2.0^{\ddagger}(1.5-2.8)$ \\
\hline No & 1 & 1 & 1 \\
\hline \multicolumn{4}{|c|}{ How long it takes to get to USC } \\
\hline$\leq 30$ minutes & $0.8(0.6-1.1)$ & $1.1(0.9-1.4)$ & $0.8(0.5-1.3)$ \\
\hline$>30$ minutes & 1 & 1 & 1 \\
\hline \multicolumn{4}{|c|}{ How difficult it is to get to USC } \\
\hline Difficulty & $1.0(0.8-1.3)$ & $0.8(0.6-1.2)$ & $1.1(0.6-1.8)$ \\
\hline Not difficult & 1 & 1 & 1 \\
\hline \multicolumn{4}{|l|}{ Services } \\
\hline \multicolumn{4}{|c|}{ Go to USC for preventive health care } \\
\hline Yes & $0.9(0.6-1.5)$ & $1.0(0.6-1.8)$ & $1.9(0.8-4.5)$ \\
\hline No & 1 & 1 & 1 \\
\hline \multicolumn{4}{|l|}{ Go to USC for referrals } \\
\hline Yes & $1.2(0.7-2.0)$ & $0.8(0.5-1.4)$ & $0.6(0.2-1.5)$ \\
\hline No & 1 & 1 & 1 \\
\hline \multicolumn{4}{|l|}{ USC provider listens } \\
\hline Yes & $0.4^{\dagger}(0.2-0.8)$ & $0.9(0.4-2.1)$ & $0.6(0.2-2.0)$ \\
\hline No & 1 & 1 & 1 \\
\hline \multicolumn{4}{|c|}{ Provider asks about other treatments } \\
\hline Yes & $1.1(0.9-1.3)$ & $0.8(0.6-1.1)$ & $0.9(0.6-1.2)$ \\
\hline No & 1 & 1 & 1 \\
\hline
\end{tabular}

Data are odds ratios (95\% confidence intervals). Logistic regressions were adjusted for the following personal characteristics: age, sex, insurance, socioeconomic status, metropolitan statistical area, census region, perceived health status, perceived mental health status, activities of daily living, and instrumental activities of daily living.

${ }^{*} P<.05$ based on test of significance of the odds ratios.

${ }^{\dagger} P<.01$ based on test of significance of the odds ratios.

${ }^{\ddagger} P<.001$ based on test of significance of the odds ratios.

USC, usual source of care.

forts should be targeted to improve access to and continuity of primary care among racial/ethnic minorities. On the other hand, the disparities in types of USC may also be an issue of concern; studies have shown that people with doctors' offices as their USC have better access to preventive care 
Table 4. Logistic Regression Odds Ratios for Attributes of Primary Care Access and Services According to Socioeconomic Status Among People With Chronic Conditions

\begin{tabular}{|c|c|c|c|}
\hline \multirow[b]{2}{*}{ Primary Care Attributes } & \multicolumn{3}{|c|}{ Socioeconomic Status } \\
\hline & High vs. Low & Above Average vs. Low & Below Average vs. Low \\
\hline \multicolumn{4}{|l|}{ Access } \\
\hline \multicolumn{4}{|l|}{ Have USC } \\
\hline Yes & $0.9(0.7-1.1)$ & $1.3(1.0-1.6)$ & $1.2(0.8-1.6)$ \\
\hline No & 1.0 & 1.0 & 1.0 \\
\hline \multicolumn{4}{|l|}{ USC type } \\
\hline Facility & $1.0(0.9-1.2)$ & $1.0(0.8-1.1)$ & $0.9(0.8-1.1)$ \\
\hline Person/Person in facility & 1 & 1 & 1 \\
\hline \multicolumn{4}{|l|}{ USC specialty } \\
\hline Primary care & $0.9(0.6-1.5)$ & $0.8(0.5-1.4)$ & $1.6(0.8-3.2)$ \\
\hline Other & 1 & 1 & 1 \\
\hline \multicolumn{4}{|l|}{ USC location } \\
\hline Office & $1.0(0.8-1.2)$ & $1.2(0.9-1.5)$ & $1.1(0.8-1.4)$ \\
\hline Hospital & 1 & 1 & 1 \\
\hline \multicolumn{4}{|c|}{ Difficulty contacting USC by phone } \\
\hline Very difficult & $1.3(0.9-1.9)$ & $1.5(1.0-2.4)$ & $1.2(0.7-2.2)$ \\
\hline Not very difficult & 1 & 1 & 1 \\
\hline \multicolumn{4}{|c|}{ USC has office hours nights/weekends } \\
\hline Yes & $1.1(0.9-1.3)$ & $1.1(0.9-1.4)$ & $1.2(0.9-1.5)$ \\
\hline No & 1 & 1 & 1 \\
\hline \multicolumn{4}{|l|}{ How long it takes get to USC } \\
\hline$\leq 30$ minutes & $1.2(0.9-1.5)$ & $1.2(0.9-1.6)$ & $1.2(0.8-1.6)$ \\
\hline$>30$ minutes & 1 & 1 & 1 \\
\hline \multicolumn{4}{|l|}{ How difficult is it get to USC } \\
\hline Difficulty & $0.7 *(0.6-1.0)$ & $0.6^{*}(0.4-0.9)$ & $0.5^{*}(0.3-0.9)$ \\
\hline Not difficult & 1 & 1 & 1 \\
\hline \multicolumn{4}{|l|}{ Services } \\
\hline \multicolumn{4}{|c|}{ Go to USC for preventive health care } \\
\hline Yes & $0.7(0.4-1.2)$ & $0.8(0.5-1.3)$ & $0.8(0.4-1.7)$ \\
\hline No & 1 & 1 & 1 \\
\hline \multicolumn{4}{|l|}{ Go to USC for referrals } \\
\hline Yes & $0.9(0.5-1.4)$ & $0.8(0.5-1.4)$ & $1.5(0.8-3.0)$ \\
\hline No & 1 & 1 & 1 \\
\hline \multicolumn{4}{|l|}{ USC provider listens } \\
\hline Yes & $0.7(0.3-1.5)$ & $0.4^{*}(0.2-0.9)$ & $0.4(0.1-1.3)$ \\
\hline No & 1 & 1 & 1 \\
\hline \multicolumn{4}{|c|}{ Provider asks about other treatments } \\
\hline Yes & $1.1(0.9-1.3)$ & $1.1(0.9-1.4)$ & $1.4^{*}(1.1-1.8)$ \\
\hline No & 1 & 1 & 1 \\
\hline
\end{tabular}

Data are odds ratios (95\% confidence intervals). Logistic regressions were adjusted for the following personal characteristics: age, race, sex, insurance, metropolitan statistical area, census region, perceived health status, perceived mental health status, activities of daily living, and instrumental activities of daily living.

${ }^{*} P<.05$ based on test of significance of the odds ratios.

USC, usual source of care.

than those with facilities as a USC, ${ }^{33,34}$ yet few studies have examined the effects of different types of USCs on quality of care and health outcomes among patients with chronic conditions. Future studies should focus on this aspect.
Another aspect of future research could target the legal and regulatory arena. To support and strengthen primary care, laws and regulations could require equitable insurance reimbursement for chronic disease management programs, increase re- 
imbursement for primary care providers, and offer incentives for preventive services targeting nonHispanic Asian, non-Hispanic black, and Hispanic populations. Developing targeted regulatory and health care policies to reduce deaths from chronic diseases and injuries would be a major step forward in eliminating health disparities in the United States. ${ }^{35,36}$

This study is subject to the following limitations. First, because of the secondary nature of the data, measures of primary care attributes have to be based on availability of data. However, as primary care is drawing more and more attention from both researchers and policy makers, comprehensive and standardized measures of primary care should be created and incorporated into national surveys such as the MEPS. Second, the representativeness of vulnerable populations in the MEPS is a challenge, as in other national surveys. This is mainly due to a variety of reasons, including language barriers, limited literacy, limited telephone accessibility of the potential responders, lack of stable addresses, and higher rates of nonresponse and loss to follow-up. ${ }^{37}$ Third, the analyses did not distinguish the differential impact of different chronic conditions. It is possible that people with different chronic conditions may experience different levels of primary care access and quality. Last, some of the variables were based on self-report, which were subject to recall or response bias and limited our ability to measure the technical quality of primary care. Also, the cross-sectional nature of this study dictates that causal inferences cannot be examined. Longitudinal analysis should be conducted in future studies.

\section{Conclusion}

Chronic conditions have caused great disease burden in the United States, and racial/ethnic disparities in access to primary care have not been eliminated among patients with chronic conditions. To achieve the goals of Healthy People 2020 and to eliminate racial/ethnic disparities, more efforts need to be devoted to racial/ethnic minorities with chronic conditions to improve their access to continuous and high-quality primary care.

\section{References}

1. Chronic disease prevention and health promotion. Chronic diseases and health promotion. Atlanta: Centers for Disease Control and Prevention; 2012.
Available from: http://www.cdc.gov/chronicdisease/ overview/index.htm/. Accessed March 26, 2013.

2. Heron $M$, Tejada-Vera B. Deaths: leading causes for 2005. Natl Vital Stat Rep 2009;58:1-97.

3. Paez KA, Zhao L, Hwang W. Rising out-of-pocket spending for chronic conditions: a ten-year trend. Health Aff (Millwood) 2009;28:15-25.

4. Thorpe KE, Ogden LL, Galactionova K. Chronic conditions account for rise in medicare spending from 1987 to 2006. Health Aff (Millwood) 2010;29: $718-24$.

5. Stuckler D. Population causes and consequences of leading chronic diseases: a comparative analysis of prevailing explanations. Milbank Q 2008;86:273326.

6. Mahmoudi E, Jensen GA. Diverging racial and ethnic disparities in access to physician care: comparing 2000 and 2007. Med Care 2012;50:327-34.

7. Miranda PY, Tarraf W, Gonzalez HM. Breast cancer screening and ethnicity in the united states: implications for health disparities research. Breast Cancer Res Treat 2011;128:535-42.

8. Mathur AK, Schaubel DE, Gong Q, Guidinger MK, Merion RM. Racial and ethnic disparities in access to liver transplantation. Liver Transpl 2010; 16:1033-40.

9. Akincigil A, Olfson M, Siegel M, Zurlo KA, Walkup JT, Crystal S. Racial and ethnic disparities in depression care in community-dwelling elderly in the united states. Am J Public Health 2012;102:319-28.

10. Shi L, Lebrun LA, Tsai J. Access to medical care, dental care, and prescription drugs: the roles of race/ ethnicity, health insurance, and income. South Med J 2010;103:509-16.

11. Levine DA, Neidecker MV, Kiefe CI, Karve S, Williams LS, Allison JJ. Racial/ethnic disparities in access to physician care and medications among US stroke survivors. Neurology 2011;76:53-61.

12. Devi S. Getting to the root of America's racial health inequalities. Lancet 2012;380:1043.

13. Kim G, Ford KL, Chiriboga DA, Sorkin DH. Racial and ethnic disparities in healthcare use, delayed care, and management of diabetes mellitus in older adults in California. J Am Geriatr Soc 2012;60:2319-25.

14. Brinjikji W, Rabinstein AA, Lanzino G, Cloft HJ. Racial and ethnic disparities in the treatment of unruptured intracranial aneurysms: a study of the $\mathrm{Na}-$ tionwide Inpatient Sample 2001-2009. Stroke 2012; 43:3200-6.

15. Eapen ZJ, Al-Khatib S, Lopes RD, et al. Are racial/ ethnic gaps in the use of cardiac resynchronization therapy narrowing? An analysis of 107,096 patients from the national cardiovascular data registry's ICD registry. J Am Coll Cardiol 2012;60:1577-8.

16. Joshi S, Gaynor JJ, Bayers S, et al. Disparities among blacks, Hispanics, and whites in time from starting dialysis to kidney transplant waitlisting. Transplantation 2013;95:309-18. 
17. Healthy People 2020 topics \& objectives. Washington, DC: U.S. Department of Health and Human Services; 2013. Available from: http://www.healthypeople.gov/ 2020/topicsobjectives2020/default.aspx/. Accessed November 16, 2012.

18. Starfield B, Shi L, Macinko J. Contribution of primary care to health systems and health. Milbank Q 2005;83:457-502.

19. Friedberg MW, Hussey PS, Schneider EC. Primary care: a critical review of the evidence on quality and costs of health care. Health Aff (Millwood) 2010;29: 766-72.

20. Starfield B. Primary care: an increasingly important contributor to effectiveness, equity, and efficiency of health services. SESPAS report 2012. Gac Sanit. 2012;26:20-6.

21. Medical Expenditure Panel Survey. Survey background. Rockville, MD: Agency for Healthcare Research and Quality; 2009. Available from: http://meps.ahrq.gov/ mepsweb/about_meps/survey_back.jsp/. Accessed June 5, 2013.

22. Ezzati-Rice TM, Rohde F, Greenblatt J. Sample design of the Medical Expenditure Panel Survey household component, 1998-2007. Rockville, MD: US Department of Health \& Human Services, Agency for Healthcare Research and Quality; 2008. Available from: http://meps.ahrq.gov/mepsweb/data_files/ publications/mr22/mr22.pdf. Accessed January 12, 2014.

23. Andersen RM. Revisiting the behavioral model and access to medical care: Does it matter? J Health Soc Behav 1995;36:1-10.

24. Starfield B. Primary care: concept, evaluation, and policy. New York: Oxford University Press; 1992.

25. Sorace J, Wong HH, Worrall C, Kelman J, Saneinejad S, MaCurdy T. The complexity of disease combinations in the medicare population. Popul Health Manag 2011;14:161-6.

26. Machlin SR, Soni A. Health care expenditures for adults with multiple treated chronic conditions: es- timates from the Medical Expenditure Panel Survey, 2009. Prev Chronic Dis 2013;10:E63.

27. Pham HH, Schrag D, O'Malley AS, Wu B, Bach PB. Care patterns in medicare and their implications for pay for performance. N Engl J Med 2007;356: 1130-9.

28. DeVoe JE, Saultz JW, Krois L, Tillotson CJ. A medical home versus temporary housing: the importance of a stable usual source of care. Pediatrics 2009;124:1363-71.

29. Pandhi N, Devoe JE, Schumacher JR, et al. Number of first-contact access components required to improve preventive service receipt in primary care homes. J Gen Intern Med 2012;27:677-84.

30. Rodriguez HP, Rogers WH, Marshall RE, Safran DG. The effects of primary care physician visit continuity on patients' experiences with care. J Gen Intern Med 2007;22:787-93.

31. Saultz JW, Lochner J. Interpersonal continuity of care and care outcomes: a critical review. Ann Fam Med 2005;3:159-66.

32. Sarver JH, Cydulka RK, Baker DW. Usual source of care and nonurgent emergency department use. Acad Emerg Med 2002;9:916-23.

33. Xu KT. Usual source of care in preventive service use: a regular doctor versus a regular site. Health Serv Res 2002;37:1509-29.

34. Atlas SJ, Grant RW, Ferris TG, Chang Y, Barry MJ. Patient-physician connectedness and quality of primary care. Ann Intern Med 2009;150:325-35.

35. Frudenberg N. Finding synergy: reducing disparities in health by modifying multiple determinants. Am J Public Health 2010;100(Suppl 1):S25-30.

36. Ladenheim K, Groman R. State legislative activities related to elimination of health disparities. J Health Polit Policy Law 2006;31:153-83.

37. Lieu TA, Newman TB. Issues in studying the effectiveness of health services for children. Health Serv Res 1998;33(4 Pt 2):1041-58. 